\title{
JUAN GUTIÉRREZ GARIBAY. VIDA Y HACIENDA DE UN GENERAL DE LA CARRERA DE INDIAS EN LA SEGUNDA MITAD DEL SIGLO XVI
}

POR

\author{
PABLO EMILIO PÉREZ-MALLAÍNA \\ Universidad de Sevilla
}

\begin{abstract}
Los cerca de quinientos generales y almirantes que mandaron las flotas de la Carrera de Indias siguen siendo en su inmensa mayoría unos perfectos desconocidos, a pesar de tener a su cargo la vital tarea de transportar millones de pesos a través del Atlántico. Por eso se presenta aqui una breve biografía de uno de los más importantes: Juan Gutiérrez Garibay, que ocupa el 5. 'lugar entre los comandantes que más convoyes llevaron a las Indias. Un hombre hecho a sí mismo, que comenzó su carrera como simple soldado y llegó durante su vejez a vivir con los lujos de un caballero.
\end{abstract}

Palabras Clave: Carrera de Indias, flotas de Indias, generales y almirantes, siglos XVI y XVII.

Juan Gutiérrez Garibay comenzó su carrera como simple soldado en 1566 y la culminó siendo almirante y general de un buen número de armadas y flotas en las que siguió navegando hasta el año anterior a su fallecimiento, ocurrido en Sevilla en 1614. Se trata sin duda de uno de los marinos más importantes de la Carrera de Indias. Sirvió a su rey en tres de las cuatro esquinas del mundo, desde las tórridas playas de Florida, a las heladas aguas del estrecho de Magallanes; participó en el intento de invasión de Inglaterra en 1588; se introdujo en 1596 con su nave almiranta entre los restos de la última expedición a las Indias de Francis Drake haciéndola huir a cañonazos, y logró, al año siguiente, escabullirse entre una armada angloholandesa de 150 buques para hacer llegar a España un vital cargamento de plata de más de 10 millones de pesos. 
Para subrayar hasta que punto Gutiérrez Garibay fue una figura importante en la historia de la Carrera de Indias, bastaría con señalar que en la relación de jefes navales que más convoyes mandaron a las Indias él ocupa un destacadísimo quinto puesto, con un total de 16 travesías del Atlántico ${ }^{1}$, una posición que adquiere mayor relevancia si se considera que fueron cerca de medio millar los militares que dirigieron alguna flota entre 1540 y 1740 .

En el cuadro que se incluye seguidamente aparecen ordenados los marinos que alcanzaron las veinte primeras posiciones en esta particular competición de resistencia náutica. La clasificación se ha establecido en función del total de viajes transoceánicos (TVT) o cruces del Atlántico que realizaron como comandantes supremos (generales) o segundos jefes (almirantes) de los convoyes indianos. Como podemos observar, Gutiérrez Garibay comparte estos puestos de privilegio con alguna de las personalidades que sirvieron más eficazmente por mar a la Casa de Austria, superando a figuras tan relevantes como Pedro Menéndez de Avilés (con trece travesías), Antonio de Oquendo (con doce), o Cristóbal de Eraso (también con doce). Del mismo modo aventaja a quienes después de haber hecho considerables servicios a sus reyes tuvieron un triste fin en su carrera, como es el caso del desgraciado Juan de Benavides y Bazán, que atravesó trece veces el Atlántico antes de que, en su último viaje de regreso, una gran parte de su flota fuese apresada en Cuba y él terminase ajusticiado por ello en la plaza de San Francisco de Sevilla.

Al interés que despierta la brillante carrera profesional de Juan Gutiérrez Garibay hay que añadir el de su atractiva trayectoria vital y personal. Fue un hombre hecho a sí mismo que, si bien en sus principios como soldado únicamente poseía la ropa que llevaba puesta, al final de sus días vivía en Sevilla como un caballero, entre colgaduras de damasco, y muebles de la China, disfrutando de rentas y de un reconocimiento político y social más que estimable.

Pues bien, a pesar de todos estos elementos que lo convierten a priori en un interesante objeto de estudio, se trata de un personaje prácticamente desconocido entre los historiadores profesionales, incluidos los especialistas en Historia Moderna de España y expertos en la Carrera de Indias. Ésta es la primera razón que me lleva a presentar aquí esta aproximación biográfica de Juan Gutiérrez Garibay. Él, como la mayoría de los comandantes de las flotas, ha sido olvidado por la historiografía y considero que es importante ir reuniendo infor-

1 Se contabiliza cada tránsito del Atlántico, tanto en sentido España-América, como en el de América-España, de tal manera que un viaje de ida y vuelta al mando de una flota se anotaría como dos travesías. En esa lista Gutiérrez Garibay ocupa la quinta posición, aunque con igual número de travesías que Carlos de Ibarra y Jerónimo de Portugal y Córdoba. 
Generales y Almirantes 1560-1740

ORDENADOS POR EL NÚMERO TOTAL DE VIAJES TRASATLÁNTICOS ${ }^{2}$

\begin{tabular}{|c|c|l|l|c|c|}
\hline Orden & TVT & \multicolumn{1}{|c|}{ Apellidos } & Nombre & Viaje inicial & Viaje final \\
\hline 1 & 34 & Larraspuru (de) & Tomás & 1608 & 1632 \\
2 & 26 & Díez de Aux y Armendáriz & Lope & 1602 & 1634 \\
3 & 21 & Vallecilla (de) & Martín & 1598 & 1634 \\
4 & 20 & Ursúa (de) y Arismendi & Pedro & 1635 & 1652 \\
$\mathbf{5}$ & $\mathbf{1 6}$ & Gutiérrez Garibay & Juan & $\mathbf{1 5 9 2}$ & $\mathbf{1 6 1 3}$ \\
6 & 16 & Ibarra (de) & Carlos & 1618 & 1639 \\
7 & 16 & Portugal (de) y Córdoba & Jerónimo & 1603 & 1613 \\
8 & 14 & Vega (de) Bazán & Juan & 1621 & 1642 \\
9 & 14 & Benavides (de) Bazán & Juan & 1613 & 1628 \\
10 & 14 & Gómez de Sandoval y Zúñiga & Jerónimo & 1611 & 1645 \\
11 & 14 & Flores de Valdés & Diego & 1567 & 1584 \\
12 & 13 & Menéndez de Avilés & Pedro & 1555 & 1574 \\
13 & 12 & Arteaga (de) & Aparicio & 1590 & 1613 \\
14 & 12 & Salas (de) de Valdés & Juan & 1591 & 1618 \\
15 & 12 & Oquendo (de) & Antonio & 1607 & 1635 \\
16 & 12 & Martínez de Leiva & Francisco & 1582 & 1593 \\
17 & 12 & Eraso (de) & Cristóbal & 1565 & 1579 \\
18 & 11 & Chaves (de) Galindo & Alonso & 1573 & 1606 \\
19 & 11 & Fernández de Córdoba Doncel & Luis & 1623 & 1641 \\
20 & 11 & Corral (del) y Toledo & Francisco & 1595 & 1607 \\
\hline
\end{tabular}

mación de este grupo profesional que tuvo que tomar decisiones realmente decisivas.

Estamos hablando, como hemos indicado más arriba, de un conjunto numeroso de personas. La cuantificación realizada por mí a través de un interesante documento del Archivo General de Indias, permite saber que fueron exactamente 434 los marinos que atravesaron el Atlántico al mando de armadas, flotas y flotillas del azogue entre 1542 y $1740^{3}$. A muchos de ellos hay que calificarlos como verdaderas figuras señeras en la historia universal de la navegación, pues si no, de que manera se podría calificar a un personaje como Tomás de Larraspuru, que cruzó el Atlántico 34 veces comandando diferentes

2 La información recogida en el cuadro se ha obtenido de la Tabla Cronológica de los generales que fueron a Yndias con flotas y Galeones y de los Gefes que fueron a comisiones particulares desde su descubrimiento, Archivo General de Indias, Sevilla (AGI), Mapas y Planos, Libros Manuscritos 80.

3 Tabla Cronológica de los generales que fueron a Yndias con flotas y Galeones y de los Gefes que fueron a comisiones particulares desde su descubrimiento, AGI, Mapas y Planos, Libros Manuscritos 80. 
convoyes; o el caso de don Lope Diez de Aux y Armendáriz, futuro marqués de Cadereyta y virrey de México, que antes de dedicarse a la administración colonial cruzó el océano 26 veces, llevando muchos millones de pesos para su rey después de atravesar mares infestados de enemigos. Pues bien, las circunstancias personales y la actuación de la inmensa mayoría de estos grandes marinos de la Carrera de Indias, salvo rarísimas excepciones, son prácticamente desconocidas ${ }^{4}$. Mala suerte tuvo el general Garibay de haber nacido en Medina del Campo, pues seguro que si un hombre de sus méritos hubiera venido al mundo más allá del Canal de la Mancha, hoy los detalles de su vida estarían recogidos en alguna biografía de las muchas que la historiografía inglesa dedica a marinos de menos merecimientos.

En agudo contraste con este descuido historiográfico por parte española, los almirantes británicos no sólo cuentan desde antiguo con estudios de conjunto ${ }^{5}$, sino con centenares de biografías individuales que, además de referirse a conocidísimas figuras como Drake o Nelson, también se ocupan de almirantes de menor renombre del siglo XVII como Blake, Monk, Montagu o el Principe Rupert ${ }^{6}$. Esta circunstancia alcanza incluso a marinos de una importancia realmente reducida como John Leake o John Lawson ${ }^{7}$, que, a pesar de todo y, por el simple hecho de navegar al servicio de Inglaterra, también han gozado de la fortuna de tener sus biógrafos. Explicar las razones de este notable desequilibrio historiográfico entre España e Inglaterra sería un tema realmente interesante, pero que excede al espacio y a la ocasión de este artículo.

Pero estudiar a los generales y almirantes de flotas también resulta atractivo porque a través de ellos podríamos ver una interesante versión de cómo los altos funcionarios ejercían el poder y su intento de control por parte del Estado. Hay que tener en cuenta que un general al mando de una flota era un repre-

4 Existen algunas biografías sobre el marqués de Santa Cruz o don Antonio de Oquendo, marinos que en realidad obtuvieron su fama en acciones realizadas fuera de las rutas indianas, pero muchas de estas obras o son antiguas o están realizadas por historiadores no profesionales. El único general de la Carrera de Indias al que los historiadores han dedicado una cierta atención es don Pedro Menéndez de Avilés, sobre el que pueden consultarse, entre otros, los trabajos que le ha dedicado Eugene Lyon: Lyon, 1974; 1995.

5 Campbell, 1750. Para el caso español existe un estudio antiguo que reúne un buen número de biografías, pero, desgraciadamente, comienza a partir del siglo XVIII dejando de lado el periodo más brillante de la Carrera de Indias: Pavía, 1873-1874. Existe otro buen compendio biográfico, pero se reduce a aquellos marinos españoles que además ocuparon cargos administrativos en las Indias: Torres Ramírez, 1992. Los almirantes de la Castilla medieval han tenido un poco más suerte: Caldera Ortega y Díaz González, 24 (Madrid, 2001): 311-364.

6 Powell, 1972. Ashley, 1977. Harris, 1912. Kitson, 1998.

7 Martin-Leake, 1920. Binns, XXXII (Leeds, 1996): 90-110. 
sentante real dotado de unas enormes prerrogativas y que las ejercía durante muchos meses en un medio completamente aislado de la interferencia de cualquier otra autoridad. Tengamos en cuenta que el jefe de uno de estos convoyes no sólo tenía que defenderse de los enemigos e impartir justicia, como hacían los gobernadores de cualquier territorio, sino que además debía vigilar la Real Hacienda, sin la colaboración de los Oficiales Reales; mantener la salud de su gente, sin tener hospitales; vigilar la moral, sin tribunales de la Inquisición y, además, hacer de albaceas y subastadores de los bienes de los muertos durante la travesía; ejercer de carceleros y alcaldes de prisiones; de agentes de emigración; de correos mayores y de tesoreros de cantidades ingentes de pesos, entre otras funciones.

Muchas de esas prerrogativas constituían, en el fondo, una ocasión y una tentación para hacerse ricos. No se trataba sólo de que los comandantes navales pudieran fácilmente convertirse en mercaderes encubiertos, sino que, simplemente, la fecha de salida de una flota constituía una información confidencial que los comerciantes locales estaban dispuestos a pagar a un alto precio, pues así sabrían hasta qué momento el flotista podía mantener los precios altos y cuándo se vería obligado a bajarlos ante la amenaza de volver a España sin haber vendido las mercancías. Resulta por ello muy interesante ver como se desarrolló esa curiosa competición en la que el Estado imponía sucesivos mecanismos con la intención de no dejarles caer en la tentación, mientras que ellos hacían todo lo posible por esquivarlos, hasta que a mediados del siglo XVII, la Corona parece darse por vencida permitiendo que los generales y almirantes tuviesen permiso para traer mercancías por importe de hasta 12.000 pesos iiy sin pagar averías!!8.

Y, en fin, resulta también de extraordinario interés el estudio de estos personajes, porque nos permitiría saber hasta qué punto su grado de formación y adecuación para ejercer sus complejas tareas pudieron influir en el buen o mal funcionamiento de las comunicaciones transoceánicas. En este sentido hay que tener en cuenta que el grupo de militares que gobernaban las armadas ejercían de jueces en las disputas laborales existentes entre los marineros y sus patronos, suponiendo en muchos casos un freno de la explotación de esta mano de obra y, por tanto, de la rentabilidad puramente comercial de los convoyes españoles. ¿Acaso la imposición de una cierta justicia laboral pudo influir negativamente en la eficacia comercial del sistema español de comunicaciones?

Creemos que estos interrogantes abiertos ponen de manifiesto la necesidad de ir conociendo las circunstancias profesionales y personales de los jefes su-

8 Veitia Linage, 1973, Libro II, Cap. I: 26. 
premos de las armadas y flotas de Indias y con esa intención se presenta aquí el bosquejo biográfico de uno de ellos: Juan Gutiérrez Garibay, que, como hemos apuntado, fue almirante y general de flotas en el último cuarto del siglo XVI y primeros años del XVII, estando en activo y - nunca mejor dicho- al pie del cañón, casi hasta el mismo momento de su muerte ocurrida en Sevilla el 14 de octubre de 1614.

Juan Gutiérrez Garibay nació en 1452 ó 1453 en Medina del Campo, un lugar bastante alejado del mar y donde las olas no se forman sobre las aguas sino sobre los extensos trigales de la meseta castellana. Su padre se llamaba también Juan Gutiérrez de Garibay y su madre fue doña Ana de Alviz, ambos también naturales de la célebre villa de las ferias. Lo que por el momento sabemos de su infancia nos lo proporciona la investigación que en 1607 se realizó en su lugar de nacimiento con motivo de su solicitud para alcanzar un hábito de la orden de Santiago 9 . La llegada de los investigadores a lo que era en el fondo un núcleo de población de unos pocos miles de personas debía ser todo un acontecimiento. Los inspectores movilizaban a cerca de medio centenar de testigos y trataban de pulsar precisamente la «opinión» y la «reputación» que existía en la villa sobre el solicitante, con lo cual es seguro que dispararían las habladurías y comentarios por toda la vecindad.

El candidato a caballero no tuvo ninguna dificultad en demostrar que pertenecía a una vieja familia hidalga de larga raigambre en Medina, pues los nombres de sus padres y abuelos estaban apuntados en un libro, llamado «de alhama» ${ }^{10}$, en el que, desde 1480 aparecía la relación de los «hijosdalgos notorios» de la localidad. Tampoco presentó problema el que más de cuarenta testigos indicaran que su familia estaba libre desde tiempos inmemoriales de cualquier entronque con moros, judíos, o conversos y que nunca habían sido penados por la Inquisición. También quedó demostrado palmariamente que ningún miembro de su estirpe había realizado oficios mecánicos, ni había ejercido el comercio al por menor, ni la usura. Inclusive los testigos afirmaron que, como rasgo visible de su condición caballeresca, lo habían visto montar y andar a ca-

9 Expediente para la concesión de hábito de la Orden de Santiago, 7 de abril de 1607, Archivo Histórico Nacional, Madrid (AHN), Órdenes Militares, Caballeros de Santiago, exp. 3707 .

10 Hoy en día se emplea ese del término árabe para denominar los antiguos barrios musulmanes y judíos de las ciudades medievales españolas, pero en este caso es posible que quisiese indicar que en él se recogían los nombres de los vecinos más ilustres de la antigua villa. 
ballo. Finalmente, se preguntó si había estado envuelto en duelos o riñas y cual había sido su comportamiento. El general no había sido hombre pendenciero, según lo que recordaban sus vecinos, pero sin duda también en ese trance hubiera dado prueba de su hidalga condición, pues como decía uno de ellos «...sabe que de ninguna manera ha sido retado y que entiende que si lo hubiera sido hubiera salido y cumplido con las obligaciones como tan honrado caballero...» $\rangle^{11}$.

Sin embargo había un tema delicado; algo que sería sin duda un secreto a voces en aquella villa castellana, pero que podría significar algún problema a la hora de convalidar su ascensión social. En las primeras preguntas de la investigación en las que se interrogaba sobre si el general cumplía la condición de ser hijo legítimo, salió a relucir una extraña circunstancia: « ¡iEl padre del general había sido "cura de misa" y su madre había sido monja en uno de los conventos más famosos de Medina del Campo!!» El hecho era recordado muchos años después ya que «se tuvo por cosa muy notoria», lo que viene a significar que debió ser el entretenimiento de los mentideros de la época. Debe reconocerse que, incluso en el ámbito del mundo católico de fechas cercanas a nosotros, podría resultar bastante embarazoso tener que explicar semejantes antecedentes familiares. Y sin embargo, aunque pueda parecernos asombroso, a los contemporáneos de Juan Gutiérrez Garibay no les extrañó tanto. Los padres del general eran pobres, pero hidalgos, y por ello no podían deshonrarse trabajando en cualquier cosa. Si no podían vivir de las propias rentas, parecía normal hacerlo de las de la Iglesia. Al fin y al cabo era una opción que centenares de personas tomaba a diario en aquella sociedad. Cierto que la mayoría elegía el camino religioso antes de casarse y tener hijos... los progenitores de nuestro biografiado, simplemente, lo hicieron después. Así contaba las circunstancias de este curioso asunto uno de los testigos:

«...La dicha su madre del dicho general, siendo doncella y soltera, había dado palabra de casarse con el dicho Juan Gutiérrez, padre del dicho general, porque la susodicha era tan principal que si no fuera debajo de esta palabra no se juntara con él, como se juntó, y que entonces el dicho Juan Gutiérrez Garibay era hombre libre y soltero y que debajo de concierto de casarse hubieron y criaron al dicho general y le criaron como tal su hijo hasta edad de cuatro o cinco años y que viendo que no se podían sustentar conforme a su calidad se concertaron que el se ordenase clérigo y ella se entrase beata en las Fajarda de la dicha villa como hicieron....» ${ }^{12}$.

11 Expediente para la concesión de hábito de la Orden de Santiago, 7 de abril de 1607, AHN, Órdenes Militares, Caballeros de Santiago, exp. 3707, fol. 34.

12 Expediente para la concesión de hábito de la Orden de Santiago, 7 de abril de 1607, AHN, Órdenes Militares, Caballeros de Santiago, exp. 3707, fol. 18-18 v. ${ }^{\circ}$ 
Entre los investigadores y los testigos se suscitó entonces una cuestión que no era baladí si el general Garibay quería llegar a caballero: ¿un matrimonio bajo palabra era válido y, por tanto, el fruto de la unión era un hijo legítimo? Muchos de los entrevistados, hay que reconocer que la mayoría, opinaron que Juan Gutiérrez Garibay era hijo natural, es decir, el habido de mujer soltera y hombre libre que en el momento del nacimiento no tenían ningún impedimento para haber contraído matrimonio. Algún testigo fue bastante contundente en la defensa de esa posición, exponiendo que aquélla era la «reputación» que tenía el general en el pueblo:

«...Ha sido público y notorio y pública voz y fama y que al dicho general Garibay no le ha tenido este testigo, ni en esta villa lo está, por de legítimo matrimonio, sino por hijo natural... y siempre ha visto estar en esta opinión y reputación de hijo natural...»13.

Sin embargo, también un nutrido grupo de testigos defendieron la legitimidad del matrimonio y del hijo habido. Se basaban en que al casarse por mutuo consentimiento los padres no hacían sino seguir «la costumbre de aquellos tiempos», cuando «no había salido el Concilio de Trento». Como es sabido, en una de las últimas sesiones del concilio, concretamente la XXIV (octava bajo el pontificado de Pío IV) que tuvo lugar en 1563, se reconocía que los matrimonios bajo palabra habían tenido validez, pero se anulaban los que a partir de entonces se hiciesen sin la presencia de un sacerdote ${ }^{14}$. Como el general había nacido en los primeros años de la década anterior, el matrimonio de sus padres parecía ser legítimo según el más estricto derecho canónico. Precisamente, entre los testigos que defendieron la legitimidad del general se encontraban varias monjas del monasterio en el que profesó la madre: el de la Visitación de la orden de Santo Domingo de las Fajardas. Muchas de ellas, ya mayores, recordaban que a doña Ana de Alviz la llamaban «la desposada» o la «desposadica», nombre, este último, que bien pudiera ser el título de cualquier novela romántica, pero que hacía indudablemente referencia a la validez de su matrimonio.

13 Expediente para la concesión de hábito de la Orden de Santiago, 7 de abril de 1607, AHN, Órdenes Militares, Caballeros de Santiago, exp. 3707, fol. 33-33 v. ${ }^{\circ}$

14 «Aunque no se puede dudar que los matrimonios clandestinos, efectuados con libre consentimiento de los contrayentes, fueron matrimonios legales.... la Iglesia, no obstante los ha detestado... el Santo Concilio manda... que en adelante... se pase a celebrarlo a faz de la Iglesia... preguntando en ella el párroco al varón y la mujer...». Sacrosanto Ecuménico y General Concilio de Trento, sesión XXIV, Decreto de Reforma sobre el matrimonio, Biblioteca Electrónica Cristiana, 2001, www.multimedios.org. 
En cualquier caso, sea por la sutileza jurídica que acabamos de comentar o porque el general tenía en sus pretensiones el decidido apoyo de un rey agradecido, su pintoresca genealogía no tuvo consecuencias a largo plazo y terminó obteniendo el hábito de Santiago. Sin embargo, su condición de hijo del «cura beneficiado de la iglesia de San Martín» y de una moja de las Fajardas y, sobre todo, la pobreza de sus padres, si que influyeron decisivamente en su infancia.

Según varios testigos el niño vivió algunos años con sus padres antes de que estos adoptasen la vida religiosa. Es posible que además de la pobreza algún otro problema impidiese el matrimonio de sus progenitores. A la madre se la llama siempre «doña» Ana, lo que es un índice de mayor alcurnia y si tenemos en cuenta que el padre de ésta, además de ser hidalgo ejercía de notario, es probable que hubiese un cierto desnivel económico entre ambos, acrecentado por el hecho de que el padre del general debía ser un simple segundón. Las decisiones importantes en la familia Gutiérrez Garibay las toma un tío del muchacho llamado Diego. Éste, finalmente, convocó algún tipo de consejo de parientes en el que se decidió la entrada en religión de los progenitores y el paso del niño a vivir con su tío ${ }^{15}$. No pasó allí mucho tiempo, pues los testigos lo sitúan viviendo después en la casa de un tal Alonso del Castillo hasta que, recién entrado en la pubertad, con doce o trece años, sus padres le dieron su única herencia, tal y como informaba un compañero de la infancia:

«...Estando este testigo en compañía del dicho general dos años en casa de Alonso de Castillo, este testigo oyó decir que era hijo de Juan Gutiérrez de Garibay... y él se ordenó clérigo y que en estos dos años le vistieron y le enviaron a Sevilla para que anduviese con su primo Juan Gutiérrez Palomar en la armada...» ${ }^{16}$.

Este tipo de situaciones puede resultar impactante en una sociedad como la española de principios del siglo XXI en la que existe una superprotección de la infancia, pero era algo común en los duros tiempos de la España del siglo XVI. Muchos hijos de gente pobres acabaron por entonces sirviendo al rey en la armada provistos por único legado, a parte de la bendición de sus padres, de la ropa que llevaban puesta y, en el mejor de los casos, de una recomendación para algún pariente, amigo o conocido, que servía en ella. Así pues, re-

15 Expediente para la concesión de hábito de la Orden de Santiago, 7 de abril de 1607, AHN, Órdenes Militares, Caballeros de Santiago, exp. 3707, folios 26 v. - $^{-27}$. «Fue público que se trató entre Diego de Garibay, que fue hermano del dicho Juan Gutiérrez, padre del dicho general, que, pues eran pobres, ella se entrase de religiosa en el convento de las Fajardas de la dicha Villa y él se hiciese clérigo de misa».

16 Expediente para la concesión de hábito de la Orden de Santiago, 7 de abril de 1607, AHN, Órdenes Militares, Caballeros de Santiago, exp. 3707, fol. 16. 
cién salido de la niñez y contando sólo con lo puesto, aparte de su propio valor, aparece el jovencísimo Juan Gutiérrez Garibay en medio de uno de los escenarios de conflictos más crueles en el que por entonces se disputaban el poder algunas potencias europeas. Me refiero a la guerra que libraron en las selvas de La Florida las tropas del gobernador y almirante asturiano Pedro Menéndez de Avilés y los hugonotes al servicio del almirante Gaspard de Coligny ${ }^{17}$.

Según su relación de méritos y servicios, había comenzado a servir al rey y a Pedro Menéndez en Florida como soldado en 1566, por lo cual no pudo estar presente en la matanza de Jean Ribault y sus compañeros acaecida en septiembre del año anterior. Posiblemente debió llegar con los refuerzos que trajeron más tarde el sobrino del adelantado, Pedro Menéndez Márquez, o su lugarteniente Esteban de las Alas ${ }^{18}$. Sin embargo, si participó en la entrada que realizó Menéndez de Avilés hacia el norte de La Florida, pues indica que fue herido en la defensa del fuerte San Pedro, que estuvo situado en tierras del actual estado norteamericano de Georgia. Se trató de una campaña durísima en la que, además de contra el clima, hubo que combatir contra los indígenas, la llegada de refuerzos hugonotes e incluso contra desertores españoles que no aguantaban las terribles condiciones de vida en aquellos fuertes hechos a base de tierra apisonada y troncos de árboles. Gutiérrez Garibay se mantuvo en ese infierno durante cinco años, para pasar en 1571 a seguir sirviendo como simple soldado en los galeones de la Armada de la Guarda de la Carrera de las Indias. Desde este momento y hasta el año antes de morir, Garibay nunca más dejaría el servicio a bordo de buques de la armada y en ella fue ascendiendo por la escala militar. En 1575, Diego de Flores Valdés, otro conocido miembro del clan de los asturianos que por entonces manejaban los resortes de la marina de guerra española, lo nombró sargento y Don Cristóbal de Eraso, que fue general de la Armada de la Guarda a partir de 1576, lo ascendió a alférez.

A partir de entonces, Gutiérrez Garibay, ya convertido en oficial, combatirá en la larga lucha que España e Inglaterra disputarían por el dominio del Atlántico y en la que el futuro general no se perdió casi ningún encuentro importante. Ascendido a capitán de mar y guerra en 1581, fue a bordo de la capitana San Cristóbal a una de las empresas más atrevidas e inútiles de la contienda: el intento de cerrar el estrecho de Magallanes a la penetración de los corsarios con la construcción de fuertes y establecimiento de guarniciones en

17 Sobre este asunto véanse, entre otros trabajos: Lyon, 1974; 1995. Crété, 1985. Acerra y Martinière, 1997.

18 Relación de méritos y servicios del capitán Juan Gutiérrez Garibay, 1566-1590, Museo Naval, Madrid (MNM), Colección Navarrete, vol. XXII, doc. 106, fol. 604. 
aquellos desolados parajes. La expedición la mandaba uno de sus antiguos jefes, Diego de Flores Valdés y aunque el resultado final de aquel empeño no tuvo las consecuencias esperadas, al menos a Garibay le sirvió para que, a su vuelta, el rey le confirmase el grado de capitán que le había otorgado el general Flores. Precisamente, sirviendo bajo las órdenes de este último general, participó en 1588 en el fracasado intento de invadir Inglaterra, logrando también volver sano y salvo de aquella empresa.

La postrera década del siglo XVI fue tal vez el momento de mayor virulencia en la guerra marítima hispano-inglesa y en ella iba a alcanzar Garibay sus principales éxitos. En 1592 y ante el peligro que suponía para las flotas de Indias la armada del conde de Cumberland, se envió una flota española a vigilar el cabo de San Vicente. En ella iba el capitán Gutiérrez Garibay bajo el mando del general Juan de Uribe Apallúa y del almirante a Pedro Sarmiento de Gamboa, otro veterano de las navegaciones por Magallanes ${ }^{19}$. Fue un viaje peligroso para los que ostentaron en ella el cargo de almirante, pues primero murió en Lisboa Sarmiento de Gamboa y más tarde su sustituto Juan de Aguirre. Todo esto le permitió a Garibay ocupar por primera vez uno de los puestos directivos de las armadas, pues fue nombrado almirante por el general Uribe en el viaje que en 1593 esta armada hizo a América para escoltar a las flotas ${ }^{20}$.

En 1595 otro importante peligro se cernía sobre las indias españolas. Una escuadra de 27 buques y 2.500 hombres capitaneados por Drake y Hawkins, los dos comandantes cosarios más famosos, amenazaba las ciudades costeras y a las flotas. Sir Francis había hecho saber a su gente que esta vez «no iba como ladrón de noche, sino como general de día» ${ }^{21}$, pero tal vez precisamente por eso la expedición fue, como es sabido, un completo desastre. Tras fracasar en Canarias, Puerto Rico (donde murió Hawkins) y en istmo de Panamá, Drake murió el 28 de enero de 1596, aunque los restos de su flota mandada por Thomas Baskerville todavía suponían una amenaza. Contra ella había partido una expedición española de 21 navíos al mando del general de la Armada de la Guarda don Bernardino González Delgadillo y Avellaneda, en la que iba como almirante Gutiérrez Garibay. El avistamiento de ambas flotas tuvo lugar frente a la isla de Pinos en marzo de 1596, e inmediatamente, los ingleses, aprovechando que tenían el fondo de sus embarcaciones recién carenados, empren-

19 Sarmiento de Gamboa, 1988.

20 Tabla Cronológica de los generales que fueron a Yndias con flotas y Galeones y de los Gefes que fueron a comisiones particulares desde su descubrimiento, AGI, Mapas y Planos, Libros Manuscritos 80.

21 Fernández Duro, 1972, t. III: 106. De la amplísima bibliografía sobre Drake una obra que resulta bastante objetiva es: Kelsey, 1998. 
dieron una rápida huida. Sólo la almiranta mandada por Garibay fue capaz de darles alcance metiéndose a cañonazos entre los enemigos, aunque sin poder impedir que los corsarios se dispersasen y lograran huir.

La valiente acción le sirvió para su definitivo ascenso al grado de general de flotas y, de esta manera, el joven soldado que en 1566 luchaba en las selvas de Florida alcanzó el mando supremo del convoy que partió hacia Tierra Firme en 1597. El momento era especialmente delicado. El año anterior la armada inglesa al mando de Charles Howard había saqueado Cádiz y en 1597 pretendía obtener el premio que más anhelaba: capturar una flota española a la vuelta de las Indias, cuando sus bodegas iban repletas de tesoros. Y éste era el caso del convoy que mandaba Garibay, el cual regresaba a España con diez millones de pesos. En las Azores esperaba una formidable agrupación de cerca de 150 buques ingleses y holandeses repartidos en varias escuadrillas y todas al mando del conde de Essex. Sin duda, éste fue el momento decisivo en la carrera profesional del flamante general de flotas, que tuvo ocasión de demostrar, no sólo sus conocimientos náuticos, sino también una equilibrada mezcla de prudencia y capacidad de decisión, que, junto con no pocas dosis de fortuna, le permitió escapar de la ratonera en la que habían caído los mercantes y su reducida escolta.

Las sesiones de las juntas de guerra habidas en el galeón capitana, Nuestra Señora de la Cinta, en octubre de 1597, muestran como el general Garibay a la hora de tomar sus decisiones escuchaba la opinión de sus principales subordinados y decidía con energía las medidas a tomar ${ }^{22}$. La llegada al archipiélago se había visto complicada por la amenazadora presencia de 30 velas enemigas pertenecientes a varias avanzadillas que los buscaban. Inmediatamente se mandó pedir información a las autoridades de las islas, que confirmaron que por las diferentes islas de Azores merodeaban por lo menos 120 buques. Estimando con certeza que tras haber sido vistos no tardarían en sufrir el acoso de conjunto de la armada enemiga, Garibay ordenó fondear las naves bajo la protección del castillo de Angra, en isla Tercera, guardó el tesoro en la fortaleza y desmontó cañones de los buques para formar baterías en la playa. De esta manera cuando el grueso de las fuerzas de Essex intentó acercarse a la costa fueron rechazadas a cañonazos. Con todo, la situación no era nada halagüeña, pues los barcos de la flota estaban expuestos, además de a un nuevo asalto inglés, a los temporales del cercano invierno en un rada poco protegida como la de Angra. Así pues, actuando con decisión y antes de que la armada de Essex

22 Junta de Guerra en Azores a bordo del galeón capitana, 9 de octubre de 1597, AGI, Patronato, legajo 255, n. ${ }^{\circ} 1$; General 5, Ramo 1. 
se reorganizase, Garibay dejó el fondeadero rápidamente y consiguió llegar a Sanlúcar de Barrameda en febrero de 1598 sin perder un solo peso del tesoro. El contento de Felipe II por este hecho, y por los millones que entraban en su hacienda, fue tan grande, que tuvo el gesto de regalarle el estandarte real que enarboló en su capitana durante la venturosa travesía. Fue un honor que Garibay recordaría toda su vida y que, como veremos, intentó que fuese también el emblema que presidiese su descanso eterno. Tras esta acción, Juan Gutiérrez Garibay fue uno de los comandantes de flota más activos y desde 1598 hasta su muerte en 1614 dirigió con éxito cinco convoyes más, tanto a Tierra Firme como a Nueva España.

Con todo, hacia 1605, con más de cincuenta años de edad y 40 de servicio, el general se sentía cansado para seguir pasando las penurias de las travesías oceánicas, que no dejaban de ser duras ni aun para los generales, por eso escribió al nuevo rey solicitando el relevo:

«...Y es notorio como ha que sirvo a Vuestra Majestad cuarenta años; los cinco en La Florida y los demás en la mar, donde he tenido a mi cargo una armada y tres flotas de que he dado la cuenta que a Vuestra Majestad es manifiesta [y] deseo acabar lo que me quede de vida en su Real Servicio en tierra. Suplico a Vuestra Majestad este intento se consiga porque aunque quiera servir bien en la mar, la edad no me da lugar a ello...» ${ }^{23}$.

El general Garibay apoyó su petición con cartas de las principales autoridades de la Nueva España en donde se encontraba al mando de una flota ${ }^{24}$. El virrey marqués de Montesclaros lo califica de «cuerdo y valiente soldado y buen marinero»; el prior del Consulado destaca haber sabido mantener siempre la «buena correspondencia y conformidad entre sus oficiales y marineros y la gente de tierra», mientras que la Audiencia destaca su condición de buen político, una cualidad que tan necesaria era en quien tenía que ser, además de comandante militar, jefe de una expedición mercantil donde entraban en colisión los intereses de los mercaderes españoles de la flota con la de los diversos puertos americanos. Por ello el alto tribunal novohispano ponía de manifiesto que el general había «procedido en el ejercicio de su cargo con mucha solicitud y vigilancia y con quietud y notable sosiego, así en los casos y cosas de la mar como en tierra y con su prudencia han cesado las competencias y disensiones ordinarias que suele haber en el dicho puerto en tiempo de flota entre los generales de las flotas, oficiales reales y castellanos del fuerte, que es justi-

23 Carta del general Gutiérrez Garibay al rey, México, 6 de abril de 1605, AGI, México, legajo 26, n. $^{\circ} 51$.

24 Carta del virrey de Nueva España al rey, México 25 de mayo de 1605, AGI, México, legajo 26, n. $^{\circ} 51$. 
cia mayor. Parecionos era justo dar aviso a Vuestra Majestad e informarle para que estimando sus servicios sea honrado...» $\rangle^{25}$.

El rey estaba dispuesto a honrar y remunerar los servicios del general, pero no disponía de tantos buenos comandantes navales como para prescindir de sus servicios. Precisamente en los años en los que Garibay pedía el relevo se detectan en las altas esferas de la administración española un gran interés por canalizar las inquietudes de muchos jóvenes españoles hacia el servicio en las armadas reales. En 1605 había terminado la guerra contra Inglaterra, que había supuesto el primer gran conflicto entre países europeos donde el principal teatro de operaciones había sido el océano. La correspondencia cruzada en los años 1606 y 1607 entre Felipe III y el duque de Medinasidonia, que ejercía como capitán general del Mar Océano, dan prueba de esta preocupación ${ }^{26}$, que culminó con la publicación de las «Ordenanzas para el aumento de la gente de mar» ${ }^{27}$, de noviembre de 1606 , complementadas por las «Preeminencias que Su Majestad se ha servido añadir a las concedidas a la gente de mar de la nación española por las ordenanzas dadas en Madrid en 4 de noviembre del año próximo de $1606 »^{28}$. Una de las prerrogativas más notables consistía en mantener la condición nobiliaria a aquellos jóvenes hidalgos que quisieran empezar a servir al rey como marineros. A decir verdad, aquella disposición era papel mojado y un empeño imposible por parte de la Corona, que no podía cambiar a golpe de Real Cédula siglos de prejuicios, pues hubiese sido impensable que cualquier hidalgo accediese a comenzar sus servicios en una profesión tan deshonrosa, que le obligaba a subir descalzo por los obenques o a llenarse las manos de ampollas tirando de cables y escotas.

Precisamente por eso, en aquellos momentos la experiencia de gentes como el general Garibay (que tampoco había empezado su carrera como marinero, sino como soldado) era más apreciada que nunca y el propio duque de Medinasidonia hacía referencia a él en una carta dirigida al rey poniéndolo como ejemplo de aquella extraordinaria generación de capitanes de mar y guerra que habían empezado luchando a las órdenes de Pedro Menéndez de

25 Carta de la Audiencia de México al rey, México 28 de mayo de 1605, AGI, México, legajo 26, n. $^{\circ} 51$.

26 Carta del duque de Medinasidonia al rey, Sanlúcar de Barrameda 26 de junio de 1606, MNM, Colección Fernández Navarrete, vol. VIII, doc. 31, fol. 217.

27 Ordenanzas para el aumento de la gente de mar, 4 de noviembre de 1606, MNM, Colección Fernández Navarrete, vol. VIII, doc. 31, fol. 220-222.

28 Real Cédula, Madrid 22 de enero de 1607, MNM, Colección Fernández Navarrete, vol. VIII, doc. 33, fol. 232. En esta Real Cédula se ampliaban las concesiones dadas por las ordenanzas de 4 de noviembre de 1606. 
Avilés ${ }^{29}$. Todo esto explica que, en los años inmediatos, los honores y las dádivas pecuniarias recompensaran los servicios del viejo general.

Ya hemos indicado que en 1607 el rey ordenó iniciar los trámites para convertirlo en caballero de Santiago y, al año siguiente, Garibay recibió el premio de una encomienda de indios en Yucatán, otorgada en principio por seis años y que le reportaría durante ese tiempo 750.000 maravedís anuales ${ }^{30}$. Teniendo en cuenta que un general de flotas sólo recibía sueldo mientras estaba al mando de los convoyes y que entonces ganaba poco más de medio millón de maravedís anuales ${ }^{31}$, la concesión real era realmente generosa. Estas prebendas apuntalaron la posición social y económica de Garibay, pero él mismo también hizo algo por su futuro. En una maniobra bastante común en la época, pero que no desmerecía de su condición de gran estratega, el general sentó la cabeza y se casó con una viuda rica.

En un documento firmado el 18 de junio de 1609 ante un escribano público de Sevilla, el general dio carta de pago al capitán Juan de Soto por la cantidad de nueve millones de maravedís en los que se había estimado la dote de la hija de éste, doña Isabel de Soto, que había contraído matrimonio con Garibay. Además de eso, la esposa terminó aportando otros 2.555.000 maravedís por la herencia de su madre ${ }^{32}$. Todo ello permitió que, a finales de la primera década del siglo XVII, aquel pobre muchacho, hijo de un cura de misa y una monja, que había dejado Medina del Campo con sólo una mano delante y otra detrás, pudiera instalarse en Sevilla y vivir como un rico caballero. Un estudio detallado de su testamento, relación de bienes y almoneda de los mismos tras su fallecimiento, pueden explicarnos cual era exactamente su nivel de vida con respecto a los demás vecinos de la capital sevillana, así como darnos idea de a que factores, además de los citados, debía su prosperidad.

29 Carta del duque de Medinasidonia al rey, Sanlúcar de Barrameda 26 de junio de 1606, MNM, Colección Fernández Navarrete, vol. VIII, doc. 31, fol. 217.

${ }^{30}$ Real Cédula, San Lorenzo 10 de abril de 1612, AGI, Patronato legajo 255, n. ${ }^{\circ}$, General 5, Ramo 1. En esta disposición se hace referencia a la Real Cédula de 20 de julio de 1608 en la que se hizo una primera concesión por seis años.

31 Eran 4 ducados al día, lo que significa 547.500 maravedís al año.

32 Sentencia de partición de los bienes de don Juan Gutiérrez Garibay, caballero de Santiago y general de galeones, entre su mujer, doña Isabel de Soto y Avilés y su hija doña María de Garibay, dictada por Justino de Chávez, teniente de asistente de la ciudad de Sevilla, 20 de octubre de 1616, Archivo Histórico Provincial de Sevilla. Protocolos Notariales, Sevilla (AHPSPN), legajo 12728, fol. 97-160. Véase también: Testamento y última voluntad de Juan Gutiérrez Garibay, Sevilla 3 de octubre de 1614, AHPSPN, Legajo 12706, fol. 867-876. 
Al final de su vida Juan Gutiérrez poseía una fortuna cifrada en 24.517.521 maravedís; se trataba de una cantidad ciertamente importante ${ }^{33}$. Los estudios que se han hecho en los últimos años sobre la riqueza de los sevillanos muestran que, en el último cuarto del siglo XVI, la media del valor de los inventarios de bienes post mortem recogidos en los protocolos notariales no pasaba de tres millones y medio de maravedís, cantidad que había subido a seis millones a lo largo de la segunda mitad del siglo XVII ${ }^{34}$. Alguno de los autores que han estudiado estos temas se atreve a fijar la frontera que daba acceso a la condición de «rico» en la sociedad sevillana de fines del XVI y principios del XVII: «...por encima de los quince o veinte millones [de maravedís], se diferencian ya claramente los ricos de la clase media y suponen el $5 \%$ de la población ${ }^{35}$.

Curiosamente el estudio de los bienes de otros antiguos generales de la Carrera de Indias asentados en Sevilla en los primeros años del siglo XVII nos muestran unos patrimonios ligeramente superiores al de nuestro biografiado, pero ciertamente semejantes. Así el general Alonso de Chaves Galindo ${ }^{36}$, dejó a su muerte ocurrida en 1608 una fortuna de algo más de 33 millones de maravedís ${ }^{37}$. Otro general, que también se asentó en Sevilla por aquellos años, Francisco de Novoa, abandonó pronto la dirección de las flotas y se dedicó a los negocios financieros, llegando a crear un mayorazgo para su única heredera de 37 millones y medio de maravedís ${ }^{38}$.

Estas cantidades de entre 25 y 40 millones de maravedís eran realmente importantes, y los colocaba en el grupo de los ricos, pero no nos engañemos, los auténticamente adinerados de la sociedad sevillana de su tiempo superaban ampliamente estos capitales. Los estudios realizados a través de los inventarios de bienes no ocultan que estos documentos sólo se redactaban ante los escribanos cuando había algún tipo de problemas de particiones de herencia ${ }^{39}$.

33 Sentencia de partición de los bienes de don Juan Gutiérrez Garibay, caballero de Santiago y general de galeones, entre su mujer, doña Isabel de Soto y Avilés y su hija doña María de Garibay, dictada por Justino de Chávez, teniente de asistente de la ciudad de Sevilla, 20 de octubre de 1616, AHPSPN, legajo 12728, fol. 97-160.

34 Rodríguez Vázquez, 1995. Aguado de los Reyes, 1996.

35 Rodríguez Vázquez, 1995: 89.

36 Este personaje, como puede comprobarse en la relación que ofrecimos más arriba, ocupa el $18 .^{\circ}$ lugar entre los generales que más viajes realizaron al mando de flotas y galeones.

37 Inventario de bienes del general Alonso de Chaves Galindo, Sevilla 7 de agosto de 1617, AHPSPN, legajo 4285, fol. 572 y siguientes.

38 Testamento y última voluntad del general don Francisco de Novoa, Sevilla 20 de enero de 1620, AHPSPN, legajo 7994, fol. 340 y siguientes.

39 Aguado de los Reyes, 1996: 21. «Al no ser obligatorio este trámite burocrático, cuando no existían problemas de reparto o litigios entre los beneficiarios, la confección del inventario - con los gastos que acarreaba - se evitaba y quedaba oculta al conocimiento general». 
Por ello, los grandes nobles sevillanos, que tenían sus patrimonios concentrados a través de los mayorazgos, no aparecen en los protocolos notariales y tampoco son frecuentes los de los grandes comerciantes. Ruth Pike señalaba que los más poderosos negociantes de la Carrera de Indias tenían patrimonios de entre 75 y 150 millones de maravedís, aunque ninguno llegó a alcanzar la fortuna de Juan Antonio Vicentelo de Leca con sus 600 millones de maravedís ${ }^{40}$. En cualquier caso y después de sus humildísimos comienzos, Juan Gutiérrez Garibay podía vivir en la sociedad sevillana con todos los rasgos externos que distinguían al señor y al caballero. Precisamente para mostrar su privilegiada posición social, de los 25 millones y medio de maravedís de su hacienda había invertido más de tres millones en lujosos enseres para adornar su casa, así como en esclavos y carruajes, cantidad ésta que se desglosaba en los siguientes apartados ${ }^{41}$ :

Ajuar de la casa
Joyas
Plata labrada
Carruajes y caballerías
Vestidos
Esclavos
Mobiliario
Armas
Cuadros
Total

$\begin{array}{rr}895.196 & 28,96 \% \\ 643.263 & 20,81 \% \\ 483.647 & 15,64 \% \\ 428.000 & 13,84 \% \\ 272.136 & 8,80 \% \\ 204.000 & 6,60 \% \\ 149.398 & 4,83 \% \\ 8.840 & 0,28 \% \\ 5.984 & 0,19 \%\end{array}$

3.090 .464

Tal vez el elemento primero y más evidente que marcaba esta distinción eran las ropas que él y su esposa podían lucir con sus respectivos aderezos de joyas. El general se podía permitir usar un jubón de tafetán negro, con cuello de holanda, calzas y coleto de ámbar, llevar al cinto una espada dorada y adornarse con una doble cadena de oro de la que colgaba una venera con la insignia de caballero de Santiago, todo lo cual costaba alrededor de 60.000 maravedís. Su esposa podía ser todavía mejor escaparate de su riqueza, ya que con sólo vestirse con uno de sus trajes de tafetán guarnecido de plata y brocado con botones de oro, llevaba encima la no despreciable cantidad de 100.000

40 Pike, 1978: 18.

41 Sentencia de partición de los bienes de don Juan Gutiérrez Garibay, caballero de Santiago y general de galeones, entre su mujer, doña Isabel de Soto y Avilés y su hija doña María de Garibay, dictada por Justino de Chávez, teniente de asistente de la ciudad de Sevilla, 20 de octubre de 1616, AHPSPN, legajo 12728, fol. 97-160. 
maravedís, y si además se adornaba con algunas de sus mejores joyas que incluían brazalete y pendientes de esmeraldas, collar de perlas y un pendiente con la cruz de Caravaca guarnecida de diamantes, había que añadir al costo de su ropa 170.000 maravedís más ${ }^{42}$. Si tenemos en cuenta que uno de los marineros de las armadas que había mandado el general Garibay ganaba 1.500 maravedís al mes ${ }^{43}$, podrá hacerse fácilmente la cuenta de que con el valor de lo que el general y su esposa podían llevar adornando sus personas en una tarde de paseo, se podía pagar el sueldo de un marinero durante i¡220 meses!!, es decir, más de 18 años de trabajo, lo que en aquellos tiempos podía significar toda una vida.

Si pudiésemos entrar al interior de su casa, nos la encontraríamos ricamente amueblada con sillas tapizadas de terciopelo carmesí y otras traídas de Moscovia o de la China, estas últimas bordadas de seda y oro. En su despacho, el general trabajaría sobre bufetes de marfil, contadores de ébano y marfil o escritorios de Alemania, todo ello valorado en unos 100.000 maravedís, pero eso sí, Garibay era un hombre de acción y en toda la casa no había un solo libro. Con diferencia, el mueble más importante y más caro de su casa era la cama, un tálamo sagrado que valía un imperio y donde los nobles, como hacían los reyes con sus cortesanos más cercanos, podían recibir a sus invitados y clientes más madrugadores. El general poseía una cama bordada de la China con su rodapié y sobrecama labrada de matices, que compró a un comerciante flamenco en 112.200 maravedís. A esa importante suma habría que añadirle los adornos, como un pabellón de damasco, una colcha bordada, almohadas de terciopelo carmesí, colchones y sábanas, incrementando su valor en 70.000 maravedís. Se podía decir que el general y su esposa dormían encima de una pequeña fortuna y eso mismo ocurría con otros miembros de la alta sociedad sevillana, que tenían en sus camas la pieza de mobiliario más valiosa. Una cama rica con dosel podía valer normalmente más de 80.000 maravedís y un importante eclesiástico, secretario del cardenal de Sevilla a fines del siglo XVI, llegó a tener un lecho valorado en 112.500 maravedís, más o menos lo que costaba el del general Garibay ${ }^{44}$.

42 El valor de estos vestidos y joyas está también sacado de la almoneda de los bienes del general que se encuentra en: Sentencia de partición de los bienes de don Juan Gutiérrez Garibay, caballero de Santiago y general de galeones, entre su mujer, doña Isabel de Soto y Avilés y su hija doña María de Garibay, dictada por Justino de Chávez, teniente de asistente de la ciudad de Sevilla, 20 de octubre de 1616, AHPSPN, legajo 12728, fol. 97-160.

43 Pérez-Mallaína, 1992: 122.

44 Rodríguez Vázquez, 1995: 126-132. Según este autor, «...La cama sigue siendo en las clases altas el mueble más mimado... a partir de la clase media toda cama destinada a un miembro de la familia es de dosel». 
La decoración principal de la casa no se hacía con cuadros. El general tenía únicamente unos retablos de lienzos de devoción y un cuadro de la virgen, valorados en 5.980 maravedís. Una cantidad ridícula si se compara con el valor de las alfombras, colgaduras, doseles, pabellones, y reposteros de telas ricas, que eran en su hogar, como en el de todos los poderosos de su tiempo, la principal forma de darle color, calidez y calidad a su residencia. Las colgaduras de damasco de la china de colores celeste, anaranjado y blanco, las piezas de brocatel blanco o una alfombra de 8 varas de largo y cuatro de ancho, costaban 575.000 maravedís, una cantidad que, según la proporción establecida más arriba, equivalía a casi 32 años de salario de un marinero de la armada.

Otros de los principales símbolos de distinción de una casa rica eran las vajillas y objetos de plata. Gutiérrez Garibay usaba este metal en sus cubiertos y platos, en las fuentes donde trinchaba sus asados, en los recipientes para sazonar los guisos, en los candelabros con que se alumbraba y hasta de plata eran los cubiletes con los que tiraba los dados. En total, la plata labrada de su casa valía más de 480.000 maravedís. Pero una vajilla de plata no sirve para mucho si no es servida por criados y lacayos. El general los tenía y además poseía tres esclavos negros de Angola, que se valoraron en 136.000 maravedís y una esclava blanca, posiblemente de origen magrebí, tasada en 68.000 maravedís.

Con todo, el lujo más propio de un caballero eran los coches y caballos. El general y su esposa se paseaban en Sevilla en una carroza valorada en 224.000 maravedís. Era un precio tan alto que no obtuvo comprador en la almoneda de sus bienes y sus albaceas decidieron llevarla a Nueva España, el lugar en donde nacía la plata y donde seguro que hallarían algún nuevo rico deseoso de adquirirla. En caso de no usar la carroza, podían pasearse en una silla de mano de terciopelo carmesí con cortinas de damasco valorada en 34.000 maravedís. Y, por supuesto, como caballero de Santiago, tenía que tener un caballo. El animal, sus arreos y alimento superaban los 100.000 maravedís.

En resumen, no hay duda que el general Garibay se trataba como un caba1lero. Pero conviene preguntarse sobre cual era el origen de su fortuna. Ya hemos indicado que hizo una buena boda y que el rey en 1608 le concedió por merced una encomienda de 750.000 maravedís anuales durante seis años, que en 1612 se le prorrogó de por vida ${ }^{45}$. Ahora bien, su sueldo como militar no creemos que diera para demasiadas alegrías. En principio los mandos de las armadas ganaban salario sólo mientras ejercían su servicio, pues cuando las armadas se desarmaban, la mayoría quedaban sin salario o, en el mejor

45 Real Cédula, San Lorenzo 10 de abril de 1612, AGI, Patronato legajo 255, n. ${ }^{\circ}$; General 5, Ramo 1. 
neros recibidos de negocios realizados en América, concentra un porcentaje estimable de sus bienes cifrado en $23,66 \%$ de su hacienda. Podemos decir que el esquema de reparto de su hacienda estaba a medio camino del noble y del comerciante. Y un detalle más podría apoyar esta situación: el general no posee casa propia. Podría decirse que eso resultaría normal en una persona cuya profesión lo ha llevado de aquí para allá y que se casó en edad ya madura. Pero es una coincidencia que, entre los grupos económicamente pudientes, sea el de los comerciantes sevillanos el que menos proporción de sus bienes destina a tener una casa en propiedad. La razón es sencilla: los rendimientos que daba el alquiler de una casa eran muy bajos, del orden del 3\% del valor de total de la vivienda ${ }^{50}$, con lo cual a un auténtico negociante le interesaba mucho más vivir de alquiler y emplear el capital en negocios de mayor rentabilidad como el comercio trasatlántico donde se obtenía rendimientos de más del $100 \%$ o incluso en juros y tributos donde fácilmente se lograban beneficios de entre el 5 y el $10 \%$.

En cualquier caso, aun sin ser un comerciante profesional, resulta evidente que el general Gutiérrez Garibay tenía negocios en Indias. Así sabemos por el inventario de sus bienes que en los dos años siguientes a su muerte diferentes maestres trasportaron a Sevilla partidas a su nombre por un importe de más de cuatro millones de maravedís, procedentes tanto de la Nueva España como de Tierra Firme. Aunque en la mayoría de los casos no se especifica a que responden estos envíos de dinero, hay que suponer que constituyen el producto de la venta de mercancías enviadas desde España. Esto queda confirmado sólo en una ocasión, cuando se detalla el envío de 200 botijas de vino tinto a Cartagena de Indias. Otras pruebas de que el general no sólo se dedicaba en sus viajes a cuidar de la moral de sus tropas, eran las diferentes partidas de dinero que le debía don Gaspar de Pereda, que como gobernador de La Habana, ocupaba un puesto clave para quien quisiese realizar cualquier trato en las rutas indianas.

¿Qué grado de legalidad tendrían todas estas transacciones? Me atrevería a responder que ya que Garibay estuvo navegando hasta un año antes de fallecer y que los generales tenían prohibido comerciar, muchos de estos negocios estarían, si no al margen de la ley, sí en una frontera cercana a la ilegalidad. Y para no andar con suposiciones basta acudir al testamento de nuestro personaje, el cual, al menos, reconoce haber defraudado al rey no pagándole algunos derechos debidos por mercancías transportadas:

«Ítem declaro que de cinco viajes en que he servido a Su Majestad con oficio de general en la Carrera de las Indias, así en los galeones como en las flotas, le seré en

50 Rodríguez Vázquez, 1995: 168. 
cargo de algunos derechos de cosas que he traído para ayuda a mi despacho hasta en cantidad de 300 ducados y quiero y es mi voluntad por descargo de mi conciencia que se paguen a su Real Hacienda si Su Majestad no fuese servido perdonármelos por los buenos servicios que le tengo hechos en cuarenta años y así fío me los perdonará» ${ }^{51}$.

Confesar deberle al rey 300 ducados por derechos impagados es lo mismo que reconocer que habría pasado sin declarar 3.000 ducados en mercancías (1.125.000 maravedís). No pagar impuestos era evidentemente ilegal. ¿Consideraría también que, aunque pagase los derechos reales, estaba faltando a su deber si se aprovechaba de su posición para hacer negocios en las Indias? Mucho nos tememos que de eso no se arrepentiría ni aun estando a las puertas de la muerte.

Ese fatal momento le llegó al general Garibay el 14 de octubre de 1614 . Hacía un año exacto que había desembarcado de su última expedición a las Indias, pues aunque había pedido retirarse hacía tiempo, el rey lo convenció para seguir en activo, concediéndole en 1612 su encomienda de por vida a cambio de dirigir una nueva flota ${ }^{52}$. Al regresar de la Nueva España era un hombre cansado, de más de sesenta años al que sólo le quedaba poner en orden sus cuentas. Algunas de éstas eran de tipo material y otras de carácter vital. En su azarosa vida de puerto en puerto sospechaba haber tenido un hijo extramarital en Galicia con una moza paisana suya, a la que mandaba buscar y darle 150.000 maravedís. Además tenía la certeza de tener otro hijo en la Nueva España, para el que dejó 750.000 maravedís. A sus lacayos y esclavas les legaba pequeñas cantidades de entre 2.250 y 4.500 maravedís y del resto de sus bienes, descontada la dote de su esposa, dejaba por heredera a su única hija legítima, Isabel de Soto y Avilés.

Finalmente, aunque como cristiano creía en la eternidad del más allá, como ser humano pretendía también vivir en la memoria de los demás, que es lo mismo que tratar de conseguir un trocito de eternidad en el más acá. Esa memoria debía aglutinarse en torno a lo que considera el hecho más notable de su

51 Testamento y última voluntad de Juan Gutiérrez Garibay, Sevilla 3 de octubre de 1614, AHPSPN, Legajo 12706, fol. 867-876.

52 Real Cédula, San Lorenzo 10 de abril de 1612, AGI, Patronato legajo 255, n. ${ }^{\circ}$; General 5, Ramo 1. En este documento se dice que se le prorrogaba la concesión de por vida teniendo en cuenta sus 45 años de servicio «...y por más servirme, aunque se halla en tanta edad, va a continuarlo por general de la flota que se apresta para la Nueva España...». 
de los casos, «reformados» con la mitad de sueldo. El salario completo de un capitán de mar y guerra era a final de siglo de 40 escudos al mes (163.200 maravedís anuales); un almirante de flotas ganaba 2 ducados al día o lo que es lo mismo 273.750 maravedís al año y un general de flota recibía, como ya hemos indicado, 4 ducados diarios, lo que equivale a 547.500 maravedís anuales $^{46}$.

La pregunta que surge inmediatamente es si Garibay habría aprovechado su posición de jefe supremo de los convoyes que cruzaban la más rica de las rutas comerciales de la época para lucrarse de una manera u otra de ella. Para responder a esta cuestión, convendría desmenuzar las partidas en las que se dividía su «cuerpo de hacienda» a la hora de ocurrir su fallecimiento en 1614 ${ }^{47}$ :

Principal de Juros y tributos

Deudas a su favor por cobrar

Mercedes reales por cobrar

Dinero procedente de Mercedes reales cobradas

Dinero procedente de negocios en Indias

Dinero procedente de deudas cobradas

Dinero procedente de Intereses de juros cobrados en 1614

Enseres y esclavos

Total del cuerpo de hacienda

$\begin{array}{rr}10.665 .680 & 43,50 \% \\ 420.392 & 1,71 \% \\ 3.000 .000 & 12,23 \% \\ 1.369 .316 & 5,58 \% \\ 4.054 .889 & 16,53 \% \\ 1.479 .770 & 6,03 \% \\ 437.010 & 1,78 \% \\ 3.090 .464 & 12,60 \%\end{array}$

24.517 .521

Es evidente que Garibay, como la totalidad de los grupos privilegiados de la sociedad sevillana, tenía la mayoría de su hacienda (un 43,50\%) invertida en renta fija, bien sobre bienes públicos (juros) o particulares (censos y tributos). Pero en esto no cumplía exactamente con el patrón de distribución de renta de los nobles y funcionarios de entonces, que solían tener aun más proporción de sus bienes (entre el $50 \%$ y el $60 \%$ ) invertidos de esta manera ${ }^{48}$. Si miramos el reparto de su hacienda vemos que tiene algunos caracteres que lo acercan al patrón esperado en un comerciante. Estos ponían menos dinero a censo (entre 15 y el $20 \%$ de su capital) ${ }^{49}$ y sin embargo concentraban el $60 \%$ de su hacienda en mercancías, dinero en efectivo y deudas por cobrar. En este sentido Gutiérrez Garibay no llega a tanto, pero entre deudas cobradas y por cobrar, más di-

\footnotetext{
46 Pérez-Mallaína, 1992: 122 y 130.

47 Sentencia de partición de los bienes de don Juan Gutiérrez Garibay, caballero de Santiago y general de galeones, entre su mujer, doña Isabel de Soto y Avilés y su hija doña María de Garibay, dictada por Justino de Chávez, teniente de asistente de la ciudad de Sevilla, 20 de octubre de 1616, AHPSPN, legajo 12728, fol. 97-160.

48 Aguado de los Reyes, 1996: 73. Rodríguez Vázquez, 1995: 81-91.

49 Rodríguez Vázquez, 1995: 81.
} 
vida: la defensa que hizo de la plata y los barcos del rey en las Azores. Un objeto servirá de símbolo de su hazaña: el estandarte real que le fue entregado por el monarca en agradecimiento por aquella acción:

«Ítem mando que después de haberse gastado en mi entierro lo que fuese menester y pagado este mi enterramiento y las deudas y mandas y legados del, quiero y es mi voluntad se saque y aparte de mis bienes la quinta parte de ellos y con lo que montare, traten y confieran entre si mis albaceas el modo como se compre fabrique y haga una capilla o entierro en la dicha Iglesia donde se traslade mi cuerpo y donde se pueda poner tendido, pendiente, en decente lugar, el estandarte real que tengo en mi casa y me hizo merced el rey nuestro señor, cuando con el favor de Dios e intercesión de Nuestra Señora de las Mercedes (a quien para esto llamé por mi abogada) libré de los enemigos en la isla Tercera, la plata y galeones que truje de las Indias a estos reinos el año de quinientos noventa y siete... advirtiendo que como quiera ha de quedar renta situada de lo que montare este quinto de mis bienes para, perpetuamente, decir en la dicha capilla o entierro una misa rezada cada día por mi ánima y de las que tengo o tuviere obligación; y el retablo que en la dicha capilla o entierro se ha de poner ha de ser de la Asunción de Nuestra Señora y todos los días que la Iglesia celebra esta santa fiesta se ha de decir cantada y muy solemne la misa en el dicho entierro o capilla» ${ }^{53}$.

La patrona y guardiana de la capellanía así fundada y, por tanto de la memoria del general, debía ser su hija y sus herederos, pero si ésta moría sin descendencia, todos sus bienes debían colocarse de manera que la capilla se ampliase y adornase con «frontales, ornamentos, escudos y letreros» y el resto emplearse en redención de cautivos. En ese caso, nombraba patrones al prior de la orden de Santiago en Sevilla y al comendador de Nuestra Señora de las Mercedes. A éstos le encargaba que cada año, llegado el día de la fiesta del nacimiento de la virgen, tomasen cada uno cien ducados de sus bienes. De los cuales se podían quedar con 40 ducados por las molestias y con el resto debían decir una misa solemne y dar una comida extraordinaria a las respectivas comunidades de la orden de Santiago y de la Merced para que, al terminar el yantar, rogasen por su alma y así suponía el general que, entre viandas y oraciones, sus compañeros de orden perpetuarían su recuerdo.

Desgraciadamente, la inmortalidad, incluso la de los recuerdos, es empresa bien ardua para los seres humanos. La iglesia en la que el general decidió enterrarse, la del convento de la Merced, no sirve hoy a ningún caballero como lugar donde esperar el Juicio Final, sino como espacio de paseo y disfrute para los turistas, pues en la actualidad es la sala principal del museo de Bellas Artes de Sevilla. En sus muros - y de eso puedo dar fe como testigo directo- no

53 Testamento y última voluntad de Juan Gutiérrez Garibay, Sevilla 3 de octubre de 1614, AHPSPN, Legajo 12706, fol. 867-876. 
queda a principios del siglo XXI rastro de ninguna capilla, ni de ningún estandarte real del siglo XVI. Por eso, me ha parecido conveniente escribir estas líneas en memoria del viejo general de las flotas de Indias, tratando de evitar que el fluir del tiempo ahogue por completo su recuerdo.

\section{BIBLIOGRAFÍA}

Acerra, Martine y Martinière, Guy, Coligny, les protestants et la mer: actes du colloque organisé à Rochefort et La Rochelle, les 3 et 4 octobre 1996, Paris, Presses de l'Université Paris-Sorbonne, 1997.

Aguado de los Reyes, Jesús, Fortuna y miseria en la Sevilla del siglo XVII, Camas-Sevilla, Servicio de Publicaciones del Exmo. Ayuntamiento de Sevilla, 1996.

Ashley, Maurice, General Monck, Totowa, New Jersey, Rowman and Littlefield, 1977.

Binns, J., «Sir John Lawson: Scarborough's admiral of the red», Northern History, XXXII (Leeds, 1996): 90-110.

Caldera Ortega, José Manuel y Díaz González, Francisco Javier, «Los almirantes del siglo de oro de la marina castellana», En la España Medieval, 24 (Madrid, 2001): 311-364.

Campbell, John, Lives of the admirals and other eminet British seamen. Conteining their personal histories, and a detail of all their public services, London, Printed for T. Waller at the Crown and Mitre, 1750.

Crété, Liliane, Coligny, Paris, Fayard, 1985.

Fernández Duro, Cesáreo, Armada española desde la unión de los reinos de Castilla y León, Madrid, Museo Naval, 1972.

Harris, F. R., The life of Edward Mountagu, K.G., first earl of Sandwich, 1625-1672, London, John Murray, Albemarle Street W., 1912.

Kelsey, Harry, Sir Francis Drake. The Queen's Pirate, New Haven and London, Yale University Press, 1998.

Kitson, Frank, Prince Rupert. Admiral and General-at-sea, London, Constable, 1998.

Lyon, Eugene, The enterprise of Florida. Pedro Menéndez de Avilés and the Spanish conquest 1565-1568, Gainesville, University of Florida Books, 1974.

Lyon, Eugene, Pedro Menéndez de Avilés, New York, Garland, 1995.

Martin-Leake, Stephen, The life of Sir John Leake, rear-admiral of Great Britain, London, Publications of The Naval Records Society, 1920. 
Pavía, Francisco de Paula, Galería biográfica de los generales de marina, jefes y personajes notables que figurarán desde 1700 a 1868, Madrid, Imprenta de F. García y Cía., 1873-1874.

Pérez-Mallaína, Pablo, Los hombres del océano. Vida cotidiana de los tripulantes de las flotas de Indias. Siglo XVI, Sevilla, Expo 92-Diputación Provincial de Sevilla, 1992.

Pike, Ruth, Aristócratas y comerciantes, Barcelona, Ariel, 1978.

Powell, John Rowland, Robert Blake: General-at-sea, London, William Collins Sons, 1972.

Rodríguez Vázquez, Antonio L., Ricos y pobres. Propiedad privada en la Sevilla del siglo XVI, Camas-Sevilla, Servicio de Publicaciones del Excmo. Ayuntamiento de Sevilla, 1995.

Sarmiento de Gamboa, Pedro, Viajes al estrecho de Magallanes, Madrid, Alianza Editorial, 1988.

Torres Ramírez, Bibiano, La marina en el gobierno y administración de las Indias, Madrid, Ediciones Mapfre, 1992.

Veitia Linage, José, Norte de la Contratación de las Indias Occidentales, Cultura Hispánica, Madrid, 1973.

Fecha de recepción: 22 de junio de 2009

Fecha de aceptación: 20 de septiembre de 2009

\section{JUAN GUTIERREZ GARIBAY. LIFE AND WEALTH OF A GENERAL OF THE TRADE CIRCUIT OF THE INDIES IN THE SECOND HALF OF THE $16^{\text {th }}$ CENTURY}

The nearly five hundred generals and admirals sent with the fleets of the Indies trade circuit continue to be, in their immense majority, perfect unknowns, even though they had under their responsibility the vital job of transporting millions of pesos across the Atlantic. That is why we present here a brief biography of one of the most important: Juan Gutierrez Garibay who occupies the fifth position among the commanders in terms of the number of convoys taken to the Indies. A self-made man, who started his career as a simple soldier, ended his life living surrounded by the luxuries of a gentleman.

KeY words: Indies trade circuit, Fleets of the Indies, Generals and admirals, $16^{\text {th }}$ century, 17 th century. 